\author{
Military Technical College \\ Kobry El-Kobbah, \\ Cairo, Egypt.
}

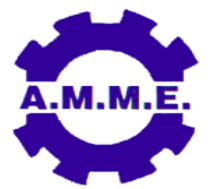

\title{
OPTIMIZATION FOR HIERARCHICAL PRODUCTION PLANNING OF INDUSTRIAL PROCESSES
}

\author{
A. A. Mahmoud ${ }^{*}$ I. H. Afefy ${ }^{* *}$ and M. Abdel-Karim ${ }^{\star * *}$
}

\begin{abstract}
In this paper, a generalized mathematical model formulation for Cellular Manufacturing System (CMS) using Hierarchical Production Planning (HPP) approach, which is a methodology to introduce the planning process by a series of mathematical models, is proposed. Particularly, the main objective of the CMS is to obtain the optimum method and this optimum method helps to solve the problem of minimizing the variable production costs (production cost, cells setup cost, inventory holding cost and regular capacity cost). Subsequently, the model is applied to two different real case studies and is solved by using operation research optimization software (Lingo-12.0 program). The model is divided into three main steps as follows: data collection, mathematical model formula, and results. The proposed mathematical model of the optimization can solve the problems of the system under utilizing the limited resources in a production plan. To prove the applicability of the proposed model, two real case studies are introduced. The results show generally that the proposed mathematical model can be used to minimize manufacturing total costs of products for similar cases. Specifically, for the first case (Electric Water Heater with capacity 50 liter (EWH1)); the results show that the total cost decreases by $8.46 \%$ for the optimum conditions. In addition, for the second case, (Electric Water Heater with capacity 80 liter (EWH2)); the results indicate that the total cost decreases by $3.7 \%$ for the optimum conditions.
\end{abstract}

\section{KEY WORDS}

Hierarchical Production Planning (HPP), Cellular Manufacturing System (CMS), Group Technology (GT), General Manufacturing Company (GMC).

* Graduate student, Dept. of Industrial Engineering. Fayoum University, Fayoum, Egypt.

** Assistant professor, Dept. of Industrial Engineering. Fayoum University, Fayoum, Egypt.

*** Professor, Dept. of Industrial Engineering, College of Engineering \& Information Technology, University of Business \& Technology, Jeddah, Saudi Arabia (On leave absence, Dept. of Industrial Engineering. Fayoum University, Fayoum, Egypt). 


\section{NOMENCLATURE}

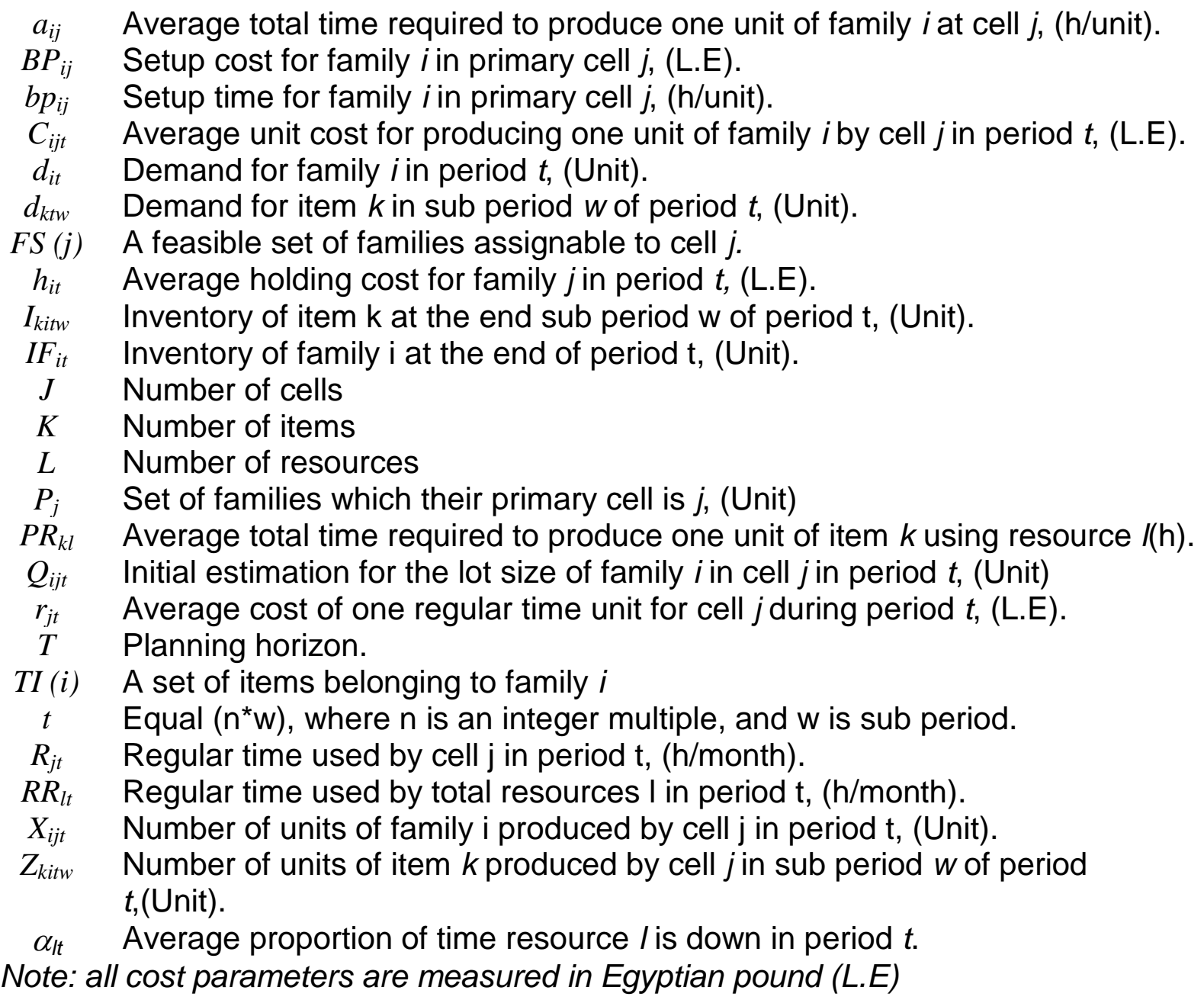

\section{INTRODUCTION}

The Hierarchical Production Planning (HPP) approach is firstly introduced by Hax and Meal [1]. In this approach, Hax and Meal structured the problem into three levels hierarchy based on types, families and items. Firstly, aggregation planning was done on types which include all production families. Secondly, families are the groups of item within type's classification. These items require a major equipment setup before they are produced. The HPP divides the large planning optimization problem known as monolithic problem into sub- problems, as illustrated in Fig. 1. From this figure, the components of different levels of aggregation for products are defined as:

1- Top level result from an aggregate planning model using linear programming and linear decision rules for variable according to its types. These types are sets of items that are similar in term of seasonal demand pattern and production rates.

2- Middle level considers a heuristic disaggregation of the type into families. These families are sets of items having similar setup costs.

3- Low level decision consists of disaggregation families that sets of items based on equalizing run out times. 
The HPP approach is necessary to demonstrate the Cellular Manufacturing System (CMS). The CMS is subset of Group Technology (GT). The GT is a new approach for batch production (small lot- production) in which similarities exist among component part or processes. While applying the GT, it depends on formation of part families on basis of design and/or manufacturing. Furthermore, applying the GT leads to a significant improvement on product design, manufacturing engineering, and the CMS [2].

Now, cell loading is a decision activity that determines the kind of items and the quantities to be produced in each cell within specific time period. The production process is subject to production capacity and demand forecast. In Batch Production (BP) environment, there are two different approaches for cell loading problem which are monolithic and hierarchal approaches. The First approach (Monolithic Approach) formulates cell loading problem as a large Mixed-Integer Linear Programming (MILP) problem at an individual item level. In this case, a heuristic procedure can be applied to solve cell loading problem. The second approach, (Hierarchical Approach) divides the overall problem into a hierarchy of smaller problems [2]. In other words, hierarchical approach is that approach which used directly toward enhancements in several ways utilizing knowledge of group technology based on manufacturing system.

Through literature, it is found that the main objective for many researchers was to obtain an optimization method to solve the problems of the system under utilizing the limited resources in a production plan to meet variability in products demand. Accordingly, the common classification for the HPP approach at many cases can be summarized as following: Goloven [3]; based on Hax and Meal, was first introduced the HPP approach for single-stage production planning and the concept of hierarchal planning through the difference between planning and operational. Goloven also modified multi-stage production planning as an extension to the HPP approach for single stage models to the systems with multi-stages. A pioneer work describing the HPP approach for the case of seasonal demand was introduced by Haas [4], as proposed a heuristic to perform the levels of hierarchical planning. Gfrerer and Zipfel [5] proposed the HPP approach for the case of uncertain demand for multi-period model. This approach consists of an aggregate planning level and a detailed planning level. Then, the same approach is modified further by Wu and lerapetritou [6]. Carravilla and Sousa [7] discussed a complex analysis production planning problem in a make-to-order company using hierarchical production planning approach. Katayama [8] proposed a relevant production planning procedure for multi-item continuous production in term of two-stage automated hierarchical planning procedure.

Incidentally, the HPP approach for complex manufacturing systems is studied in details by Mehraz et al. [9]. Akturk and Wilson [2] discussed the CMS by proposing a hierarchical cell loading approach to solve the production planning problem. Ozdamar and Birbil [10] described the HPP approach for the case of energy intensive production environment for energy intensive industries (e.g. steel, tile and glass ware industries). Hence, Ozdamar and Birbil minimized the number of active kilns throughout the year besides optimizing the process design in the curing department. Aghezzaf et al. [11] investigated a robust HPP approach for a two-stage 
real world capacitated production system operating in an uncertain environment. Achmed et al. [12] developed multi objectives model using Lingo program (software).

In this work, the HPP approach has been applied to the CMS plant of the General Manufacturing Company (GMC). Hence, a conceptual framework and a mathematical model are proposed for the CMS. The basic principles of calculations of the method for the CMS model are shown in details, starting from formulating a Lagrange relaxation and ending with using optimization software program Lingo (12.0) to solve mathematical model. Moreover, a flowchart for framework algorithm elucidating steps of solving the problem is carried out and presented. Finally, the proposed model is applied to two different real case studies and is solved by using operation research optimization software (Lingo program) in order to obtain the optimum method of solving the problem of minimizing the variable production costs. It is found that, the total products costs are saved for the two case studies by using the HPP approach for the CMS.

\section{METHODOLOGY}

In this work, the CMS problem is solved using Lingo program which is a comprehensive tool designed to make building and solving mathematical optimization models easier and more efficient. Lingo (12.0) provides a completely integrated package that includes a powerful language for expressing optimization models and a full-featured environment for building and editing problems. In addition, it has a set of fast built-in solvers capable of efficiently solving most classes of optimization models.

\section{Mathematical Modeling}

Two main parts for solving the CMS problem will be summarized in this section. The first part illustrates objective function and the second part defines the mathematical formulation; as described briefly in the following subsections.

\section{Objective function}

The objective function is to minimize variable production cost, such as (production cost, cells setup cost, inventory holding cost and regular capacity cost). These variables can be simplified as:

$$
\operatorname{Min}(\operatorname{Cos} t)=\sum_{t=1}^{4} \sum_{j=1}^{7}\left(\sum_{i=F S(j)} C_{i j t} X_{i j t}+\sum_{i \in P_{j}}\left(B P_{i j} / Q_{i j t}\right) X_{i j t}+r_{j t} R_{j t}\right)+\sum_{t=1}^{4} \sum_{i=1}^{2} h_{i t} I F_{i t}
$$

\section{Mathematical formulation}

There are three types of constraints at hierarchical model for cell loading problem in the CMS. These constraints can be defined as:

- Production Constraints for families and items described by Eqs.(2) and (3).

- Inventory Constraints for families and items described by Eqs.(2), (3), and (4). 
- Production and resources capacity constraints over the planning horizon described by Eqs (5), (6), (7), (8), and (9)), respectively.

$$
\begin{aligned}
& \sum_{j=1}^{7} X_{i j t}+I F_{i, t-1}-I F_{i t}=d_{i t}, \quad \text { for } \mathrm{j}=1,2,7, \quad \mathrm{t}=1,2, \ldots 4 \\
& \sum_{k \in T I(i)} \sum_{w=I}^{n} I_{k t w}-I F_{i t}=0 \\
& \sum_{i \in F S(j)} a_{i j} X_{i j t}+\sum_{i \in P_{j}}\left(b p_{i j} / Q_{i j t}\right) . X_{i j t}=R_{j t} \\
& 0 \leq R_{j t} \leq(\text { upperlimit }) \quad \forall j \\
& \sum_{i \in F S(j)} \sum_{k \in T I(i)}\left(P R_{k l} \sum_{w=I}^{n} Z_{k j t w}\right)=R R_{L T} \quad \forall L \in L R(j), j, t \\
& 0 \leq R R_{L t} \leq(\text { upperlimit }) .\left(1-\alpha_{L t}\right) \quad \forall L, t \\
& \sum_{l \in L R(j)} R R_{L t}-R_{j t}=0
\end{aligned}
$$

With respect to :

$$
X_{i j t}, I F_{i t}, O_{j t}, R_{j t}, Z_{k j w}, I_{k t w}, O R_{L t}, R R_{L t} \geq 0 \quad \forall j, t
$$

The most important part in this study is the conceptual framework and mathematical model which were proposed for the CMS. The study shows the basic principles for calculations of the method for the CMS model. This is obtained through; define Lagrange theory, apply decomposition procedures, update the values of Lagrange method using gradient method and use optimization software program Lingo (12.0) to solve mathematical model. Moreover, the flowchart of the framework algorithm is carried out. This chart provides in details the whole steps for solving the problem, where the final part is devoted to illustrate the proposed software methodology in solving the mathematical optimization models in an easier and more efficient way.

As a matter of fact, Akturk, and Wilson [2] stopped at using Lagrange theory without providing any solution by any means. In the current work, however, the proposed solution complements the work of Akturk, and Wilson as it consists of formulating a Lagrange relaxation for the initial model, solving this dual problem by efficient and iterative solution procedures, applying decomposition procedures, updating the values of Lagrange method using gradient method and using optimization software program Lingo (12.0) to solve the mathematical model.

\section{CASE STUDY}

The considered case study is applied at General Manufacturing Company (GMC) for manufacturing engineering in Egypt. The company manufactures three products: full automatic washing machine, gas cooker and Electrical Water Heaters (EWH) with 
capacity of $(30,40,50,80,100$ Liter). The main interest in this work is studying the last product i.e. the EWH especially with the capacity of $50 \mathrm{~L}$ and $80 \mathrm{~L}$ in details. Hence, the proposed mathematical model is applied through the data collection as a first step then through mathematical formula as a second step and finally through obtaining results in the last step.

\section{Problem Statement}

In this part, the problem of planning production in this application is described. First, the problem statement is discussed, and then the solution method is introduced. In general, systems play an important role in many industrial processes. Particularly, the main objective of the CMS is to obtain the optimum method to solve the problem of minimizing the variable production costs (production cost, cells setup cost, inventory holding cost and regular capacity cost). The main objective from the case study is to minimize the total product cost, consequently increase profitability. Therefore, the HPP approach is applied and utilized for solving this problem. To achieve this target, it is necessary to manage and control the relation between the limited resources in the plan of the production and variability in products demand.

\section{Solution Method}

A schematic flowchart for the framework of the algorithm used in the CMS is illustrated in details in Fig. 2. Using this algorithm provides optimal solution for the system. It should be noted that, the algorithm consists of three main steps named as: data collection, mathematical model and results. These steps are discussed briefly too in the next subsections. This schematic is introduced and explained in more details in Appendix $(A)$ in addition to the required steps for the optimal solution.

\section{Data Collection}

In order to illustrate the capabilities of the proposed-model, actual data from the GMC with emphasis on Electric Water Heater (EWH) product have been collected. A comprehensive numerical example is presented to illustrate the applicability of the proposed model in such environment. This example is solved with the Lingo (12.0) software.

In this case, all different types of cost parameters that are used for the computational study are presented. The data collections for the considered case study are focused mainly on two families of the EWH which are electric heater water with capacity of $50 \mathrm{~L}(\mathrm{EWH} 1)$ and that one with capacity of $80 \mathrm{~L}(\mathrm{EWH} 2)$. The different variable parameters in the system are summarized in Table 1, where $U N \sim[a, b]$ represents a uniformly distributed random variable in interval [a, b]. It should be noted that, most of the value of these parameters are constant throughout the planning horizon. In addition, the processing time of each item at each feasible resource $\left(P R_{k l}\right)$ and the number of operations for each item are fixed. Moreover, these parameters listed in Table 1 are used through the mathematical model in addition to the following conditions:

(i) Seven manufacturing cells;

(ii) Four planning horizon period (four weeks); 
(iii) Five resources of production (machine, manpower, material, maintenance - spare parts - and energy);

(iv) Fifty-six (parts) items;

(v) No secondary cells in production;

(vi) No overall overtime;

(vii) No backorder;

(viii) $P 1, P 2, \ldots \ldots, P 7=\{$ family 1,2$\}$, where $P 1$ is a set of families at primary cell(1);

(ix) $\quad F S(1), \ldots \ldots \ldots, F S(7)=\{$ family 1,2$\}$ where $F S(1)$ is a feasible set of families assignable to cell (1);

(x) TI (1) =TI (2) =65 items, where TI (1) is a set of items to family (1); and

(xi) $\quad \operatorname{LR}(1)=\operatorname{LR}(2), \ldots \ldots ., \operatorname{LR}(7)=\{$ resource $1,2,3,4,5\}$, where $\operatorname{LR}(1)$ is a set of resources belonging to cell (1).

\section{RESULTS}

In this section, the results for the two different cases under consideration, will be presented and discussed in details. Where, two comprehensive examples with full input data and results analysis are presented. First, let us consider the first product i.e., the EWH1 product. Comparison between the obtained numerical results of the initial and optimum total product cost indicted that there is a significant reduction in the total product cost of EWH1. Hence, the optimum total product cost (Z) of EWH1 decreases to $4.1^{*} 10^{8}$ L.E rather than $4.48^{*} 10^{8} \mathrm{~L}$.E with respect to its initial values. Approximately $8.43 \%$ of the total product cost for the EWH1 can be saved according to the optimized results.

As a matter of fact the significant decrease in the total product cost can be attributed to the optimal values obtained for each parameter included in the mathematical model. In order to clarify the results in details, the initial and the optimal values for the different parameters are listed in Table 2. It should be noted that there are fifteen parameters are listed in this table, however critical scrutiny for this table indicates that, there is notable improvement specifically at only three parameters or effective variables parameters which called as the most effective parameters in the model. Therefore, these variables are considered in details as shown in Fig. 3, which illustrates a pictorial comparison between their initial and optimal values for the case of EWH1. These effective parameters have a notable difference between their initial and optimum values which cause the significant decrease in the total product cost. For example, inventory of the product at the end of planning period decreases from 1295 unit/ month in the initial conditions to 1275 unit/ month in the optimum conditions. This indicates that the total product cost will decrease with the decrease of the inventory cost. Also, this table shows the average cost of one regular time unit of cell which decreases from 21164.73 L.E in the initial conditions to 20251.47 L.E in the optimum conditions resulting also in overall decrease in the total product cost.

Incidentally, same features are observed also for the second case which is EWH2, where significant difference between the initial and the optimum total product cost as obtained from Lingo program is observed. In this case, an approximately $5.4^{*} 10^{6} \mathrm{~L}$.E was saved according to the optimized results. This means that a noteworthy 
reduction in the total product cost of the EWH2 also can be obtained by using a suitable optimum technique. To discuss these results in details, a comparison between the initial and the optimum variable values is presented in Table 3. Again, critical scrutiny for this table indicates that, there is a notable improvement also in specific effective variables parameters and as a result the optimum total product cost decreased in comparison with the initial value. For example, it is listed that the average cost of one regular time unit of cell decreases from 36751.25 L.E in the initial conditions to 36001.29 L.E in the optimum conditions. Approximately $4.04 \%$ of the total product cost was saved according to the optimization results in the case study of (EWH2). As a matter of fact, these results agree fairly well with the results of Akturk and Wilson [2].

For more elucidation let us discus the data shown in Table 3 regarding the effective variable parameters in this case (EHW2). The effective variable parameters in this case are presented and analyzed as shown in Fig. 4. From this figure, it is observed that there are particular improvements at these variables resulting in the overall reduction of total product cost. For example, initial estimation for the lot size of the product in cell at planning period decreases from 2055 unit/ month in the initial conditions to 2047 unit/ month in the optimum conditions. Also, the total product cost is decreased with respect to the decrease of the production cost.

\section{SENSITIVITY ANALYSIS ON THE OPTIMIZATION MODEL FOR CMS RESULTS}

In order to carry out an acceptable and dependable analysis to show the sensitivity of the problem developed for the CMS using the HPP approach, the different parameters utilized in the case study for both the EWH1 and the EWH2 are examined critically with emphasis on some effective variable parameters defined as: $X_{i j t}, Q_{i j t}, I F_{i t}, d_{i t}$, and $R_{i t}$. Therefore, the values for these parameters that resulted in minimizing the total product cost are chosen to be used for such sensitivity analysis. The sensitivity of the approach against variations in the numbers of $X_{i j t}, Q_{i j t}, I F_{i t}, d_{i t}$, and $R_{i t}$ are presented in Figs. 5, 6, 7, and 8. Where, these figures show the effective variable parameters for (EWH1, EWH2) against the variance and the variance percentage $(\%)$ respectively. Here, it should be noted that, the variance $(\Delta \mathrm{V})$ is defined as the difference between the initial value (IV) and the optimum value (OV) of the parameter and the variance ratio $(\Delta \mathrm{V} \%)$ is defined as the percentage ratio between the variance of the parameter $(\Delta \mathrm{V})$ and its initial value (IV). In general the results presented in this section agree fairly well with the results of the sensitivity analysis performed by Tariq [13] and Aljuneidi [14].

The effective variables parameters for the first case (EWH1) are illustrated in Fig. 5. In this figure, the effective variables are illustrated with respect to their variance value $(\Delta \mathrm{V})$ tabulated in Table 2 . From this figure, it is clear that the most significant variable among theses effective ones is the variance value for the variable $R_{j t}$, where, $\Delta \mathrm{V}=913.26 \mathrm{~h} /$ month. Now let us define this value according to the variance value for the total product cost listed in Table 1 . However, it should be noted that a common ratio for these two variance values cannot be obtained since they have different units. On the other hand, the relative weight value can be expected from the comparison between these two values, i.e. it can be said that, the variable $R_{j t}$ (which 
has variance equal to $913.26 \mathrm{~h} /$ month) has a certain effect in minimizing the total product cost and this effect will be greater than the other variables.

For further clarification, the variance ratio $(\Delta \mathrm{V} \%)$, for these effective parameters are pictorially illustrated in Fig. 6 while the value of the variance ratio for the whole parameters are listed in Table 1. Again, from this figure it can be said that, the variable $\left(R_{j t}\right)$ is an effective variable but not the most effective one since its variance ratio is equal to $4.32 \%$ and it has a significant effect in reducing the total product cost for the considered case study. However, from this figure it can be pointed out that, the most effective variable parameters on the variance ratio $(\Delta \mathrm{V} \%)$ is the parameter Qijt $(\Delta \mathrm{V}=21.45 \%)$. This means that the most effective parameter in variance is not the most effective one in the variance ratio and vice versa. Therefore, it can be said that both variance and variance ratio; $\Delta \mathrm{V}$ and $\Delta \mathrm{V} \%$ (both of them not only one of them) are necessary to identify the effective parameters. However, in general, these effective variables which have either maximum variance $(\Delta \mathrm{V})$ or maximum variance ratio $(\Delta \mathrm{V} \%)$ have a specific effect on at the minimization of the total product cost. In addition, as shown in Fig. 6, there are two equal effective variables which are $X_{i j t}$ and $d_{i t}$ having the same variance $(\Delta \mathrm{V})$ and same variance ratio $(\Delta \mathrm{V} \%)$; therefore they are having the same effect on minimizing the total product cost. However, it could happen that two effective variables have the same variance $(\Delta \mathrm{V})$ but it is not necessary to have the same variance ratio $(\Delta \mathrm{V} \%)$.

As a matter of fact, the same observations can be deduced from Figs. 7 and 8 which introduce the variance $(\Delta \mathrm{V})$ and variance ratio $(\Delta \mathrm{V} \%)$ for the effective variable parameters (i.e. the sensitivity analysis) for the second case, EWH2. In addition, values of the variance $(\Delta V)$ for the two case studies $(E W H 1$ \&EWH2) regarding the total product cost are illustrated in Fig. 9. Moreover, the most important results that can be directly concluded from Fig. 10 which shows the total product cost saved for the two cases (EWH1 \& EWH2). However it should be memorized that these amounts can be saved if and only if the proposed mathematical model is used. In other words, it can be concluded from the analysis of the effective variable parameters presented above that the performance of the proposed algorithm is satisfactory. The total products costs are saved for the two products and this aim achieved by using the HPP approach for the CMS, which saved $37.85^{\star} 10^{6} \mathrm{~L}$.E (8.43\%), 54.57*106 L.E (4.04\%), respectively.

\section{CONCLUSIONS}

In this paper, the HPP approach is applied to CMS plant of General Manufacturing Company (GMC). Particularly, the main objective of the CMS is to obtain the optimum method to solve the problem of minimizing the variable production costs. Thus a mathematical model is developed and applied to two different real case studies. A conceptual framework and mathematical model are proposed for CMS. Moreover, a flowchart for framework of algorithm is carried out. The proposed mathematical model is solved using the Lingo program and presentable results are obtained. It is found that there are notable improvements in many variables which reflect the reduction of the total product cost. This reduction leads to achieve the optimum condition at the system. These variables sound great effects as they are 
significant for current study but they could be variable for another. Finally, comparison among optimized results and initial values indicates that significant reduction in the total cost can be obtained by applying such technique for any similar manufacturing systems.

As a matter of fact, development of a mathematical model under more variables parameters such as costs, processing routes and machine availability is recommended for further studies. In addition, aggregating model with other assumptions like layout problem considerations for the CMS and layout design for the CMS are also important and should also be taken into considerations.

\section{ACKNOLEGEMENTS}

The authors express their thanks to the staff members of the GMC Company, Egypt, for their support during collecting the dada included in this work

\section{REFERENCES}

[1] A. Hax,.and C. Meal, "Hierarchical Integration of Production Planning and Scheduling," in Logistics, M. A. Geisler, ed., North Holland, Amsterdam, pp. 53-69, (1975).

[2] M. Akturk, and G. Wilson, "A Hierarchical Model for the Cell Loading Problem of Cellular Manufacturing Systems", Int. J. of Prod. Res., Vol. 36, pp. 20052023, (1998).

[3] J. Goloven, "Hierarchical Integration of Planning and Control", Ph. D. Thesis, Cornell University, August (1975).

[4] E. Haas, "Hierarchical Production Planning", Ph.D. Thesis, Massachusetts Institute of Technology, (1979).

[5] A. Gfrerer and G. Zipfel, "Hierarchical Model for Production Planning in the Case of Uncertain Demand", Eur. J. of Oper. Res., Vol. 86, pp. 142-161, (1995).

[6] D. Wu and M. lerapetritou, "Hierarchical Approach for Production Planning and Scheduling Under Uncertainty", Chem. Eng. Proc., Vol. 46, pp. 1129-1140, (2007).

[7] M. Carravilla and J. Sousa, "Hierarchical Production Planning in a Make-ToOrder Company: Case Study", Eur. J. of Oper. Res., Vol. 86, pp. 43-56, (1995).

[8] H. Katayama, "On a two-stage Hierarchical Production Planning System for Process Industries", Int. J. of Prod. Econ., Vol. 44, pp. 63-72, (1996).

[9] A. Mehraz, I. Minis and J. Proth, "Hierarchical Production Planning for Complex Manufacturing Systems", Advances in Eng. Software, Vol. 26, pp. 209-218, (1996).

[10] L. Ozdamar, and S. Birbil, "A Hierarchical Planning System for Energy Intensive Production environments", Int. J. of Prod. Econ., Vol. 58, pp. 115129, (1999).

[11] E. Aghezzaf, C. Sitompul and F. Broecke, "A Robust Hierarchical Production Planning for a Capacitated Two-Stage Production System", Comp. Ind. Eng., Vol. 60, pp. 361-372, (2011). 
[12] H. Achmad, H. Muh, S. Wahyudi and W. Kuncoro, "A Relationship Model between Supplier and Manufacturer for Securing Availability of Teak Log in Export Oriented Furniture Industry with Sustainability Considerations", Proc. Int. Multi-Conf. of Eng. and Comp. Sci., Hong Kong, March (2012).

[13] A. Tariq, "Operational Design of a Cellular manufacturing System", Ph. D. Thesis, National University of Science and Technology (NUST), Rawlpindi, Pakistan, (2010).

[14] T. Aljuneidi, "A Mathematical Approach to the Design of Cellular Manufacturing System Considering Dynamic Production Planning and Worker Assignments", Ms. C. Thesis, Concordia University, Montreal, Quebec, Canada, (2013). 


\section{Appendix A}

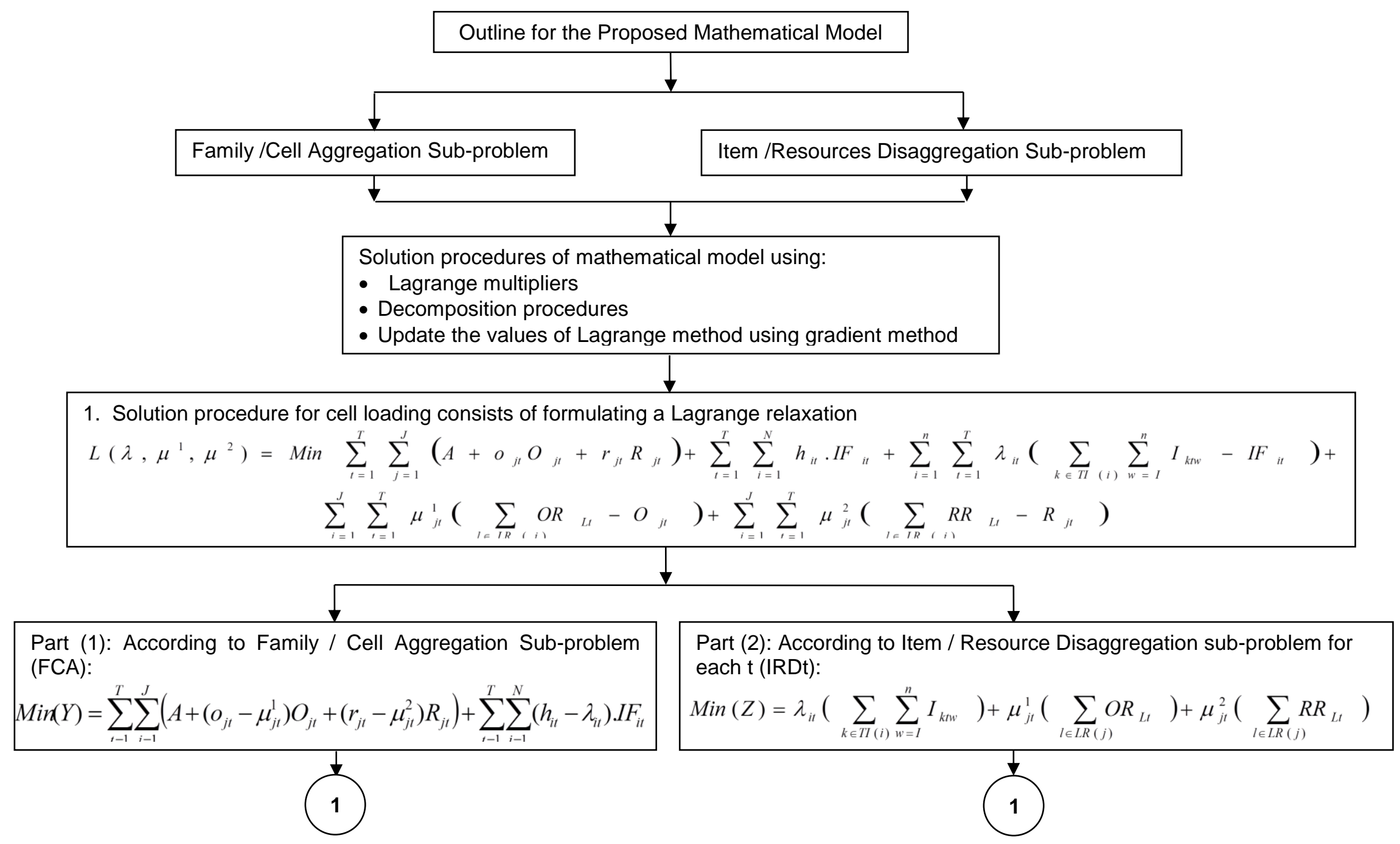




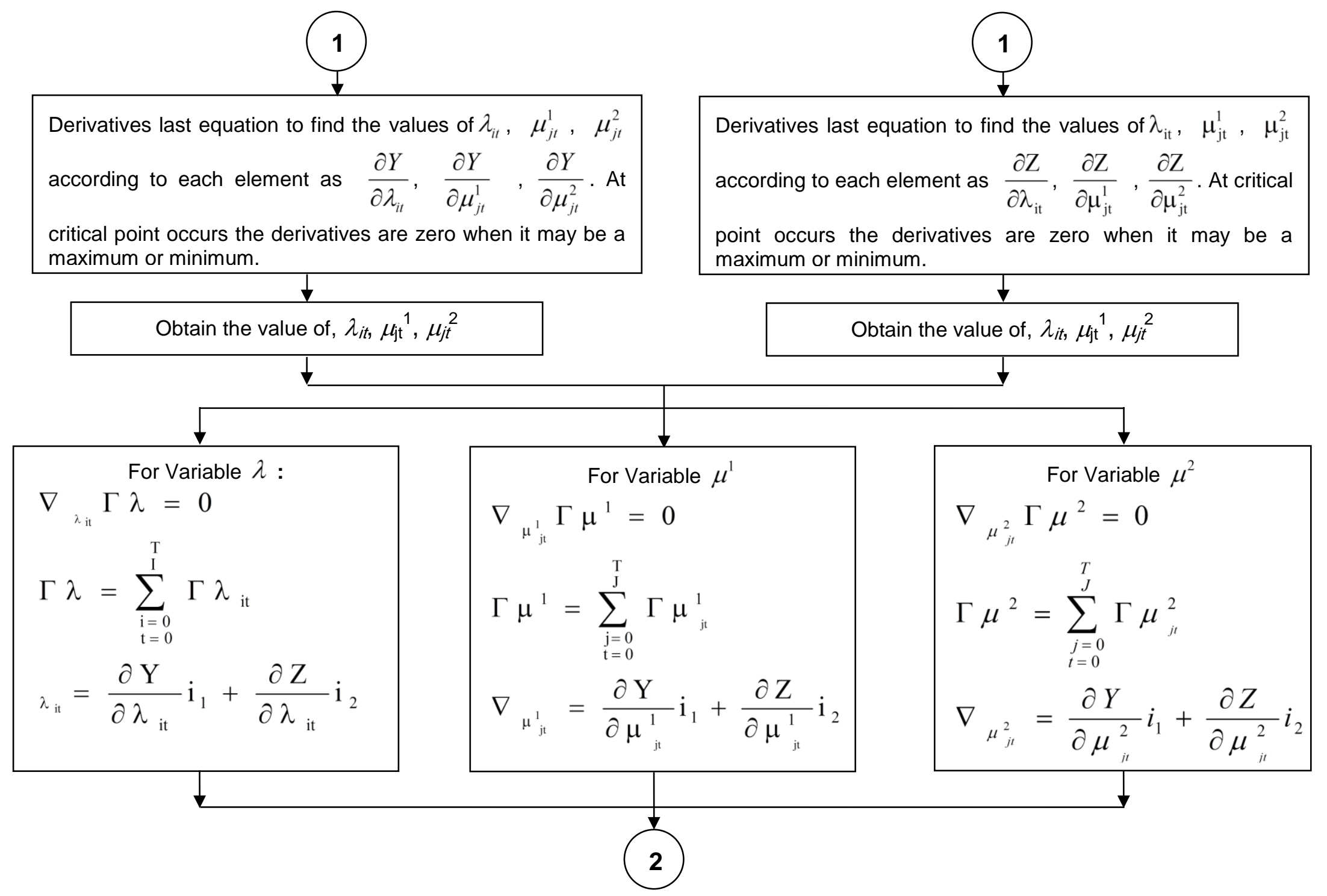




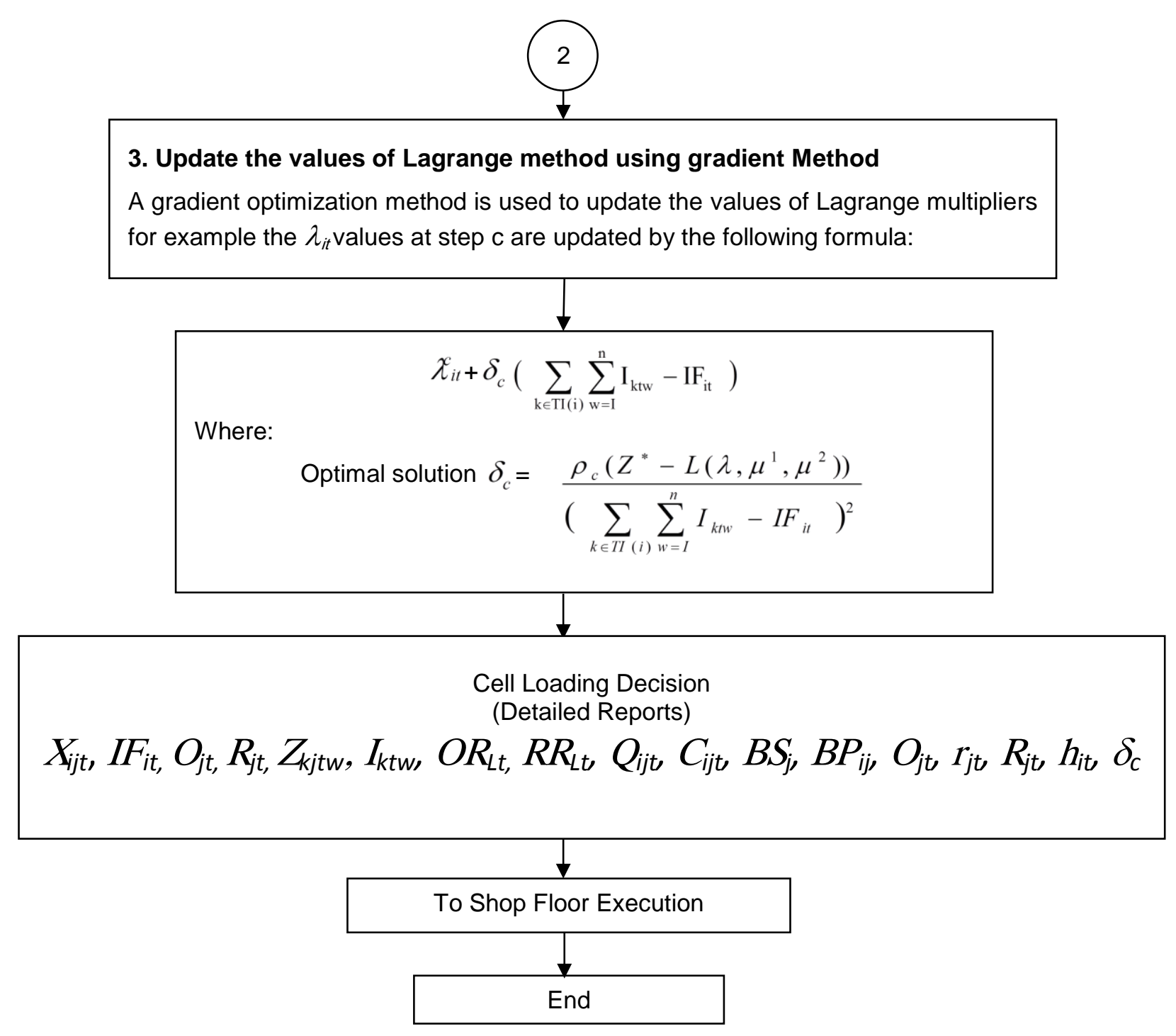




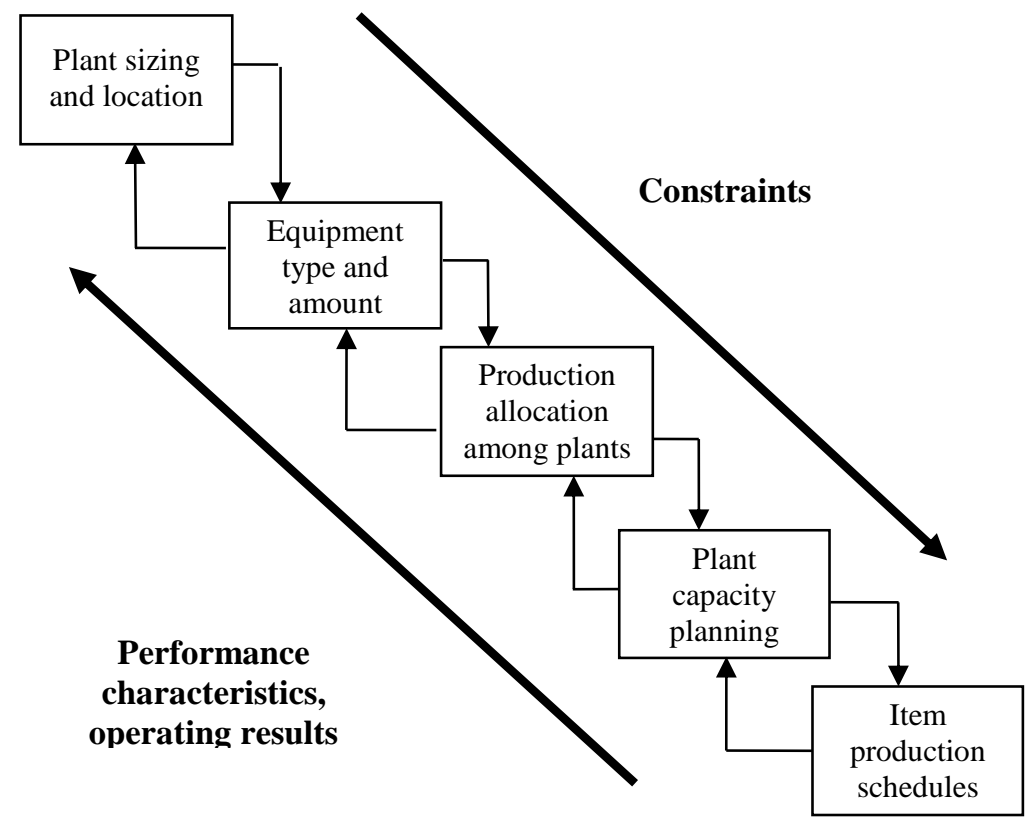

Fig. 1 Components of different levels of aggregation for products

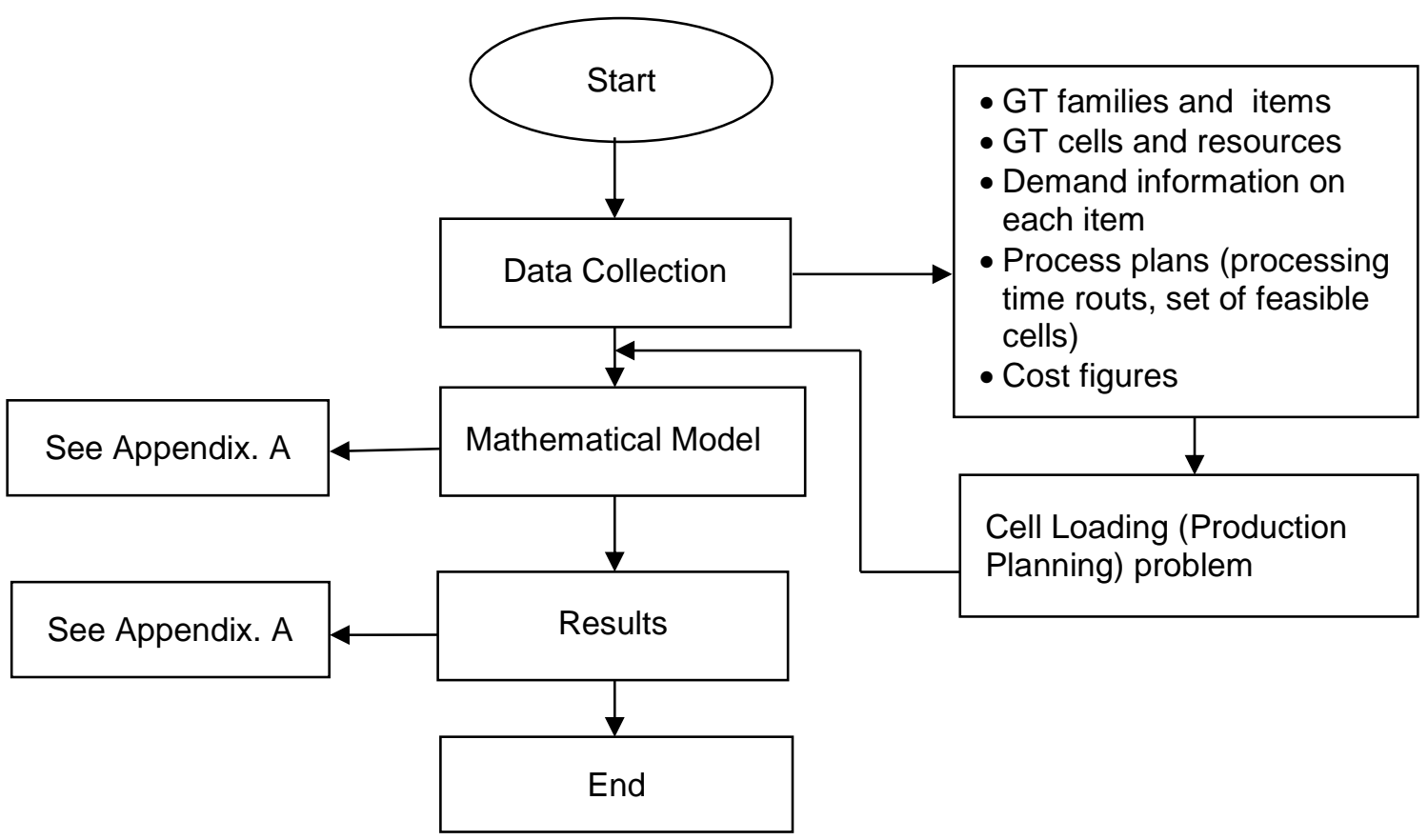

Fig. 2. Schematic flow chart of algorithm used in the CMS 


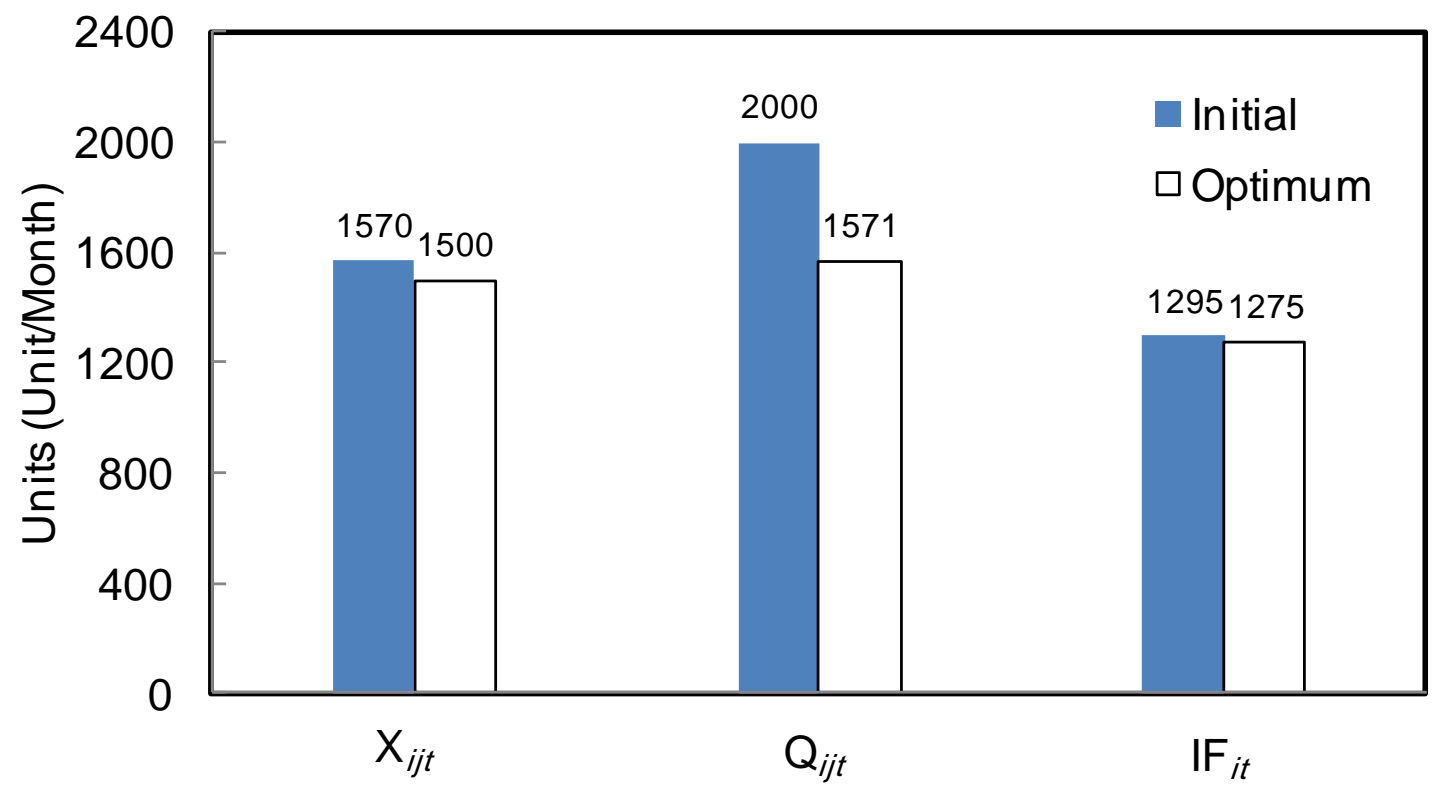

Effective Variable Parameters for EWH1

Fig. 3. Comparison between initial and optimal values of variables for EWH1.

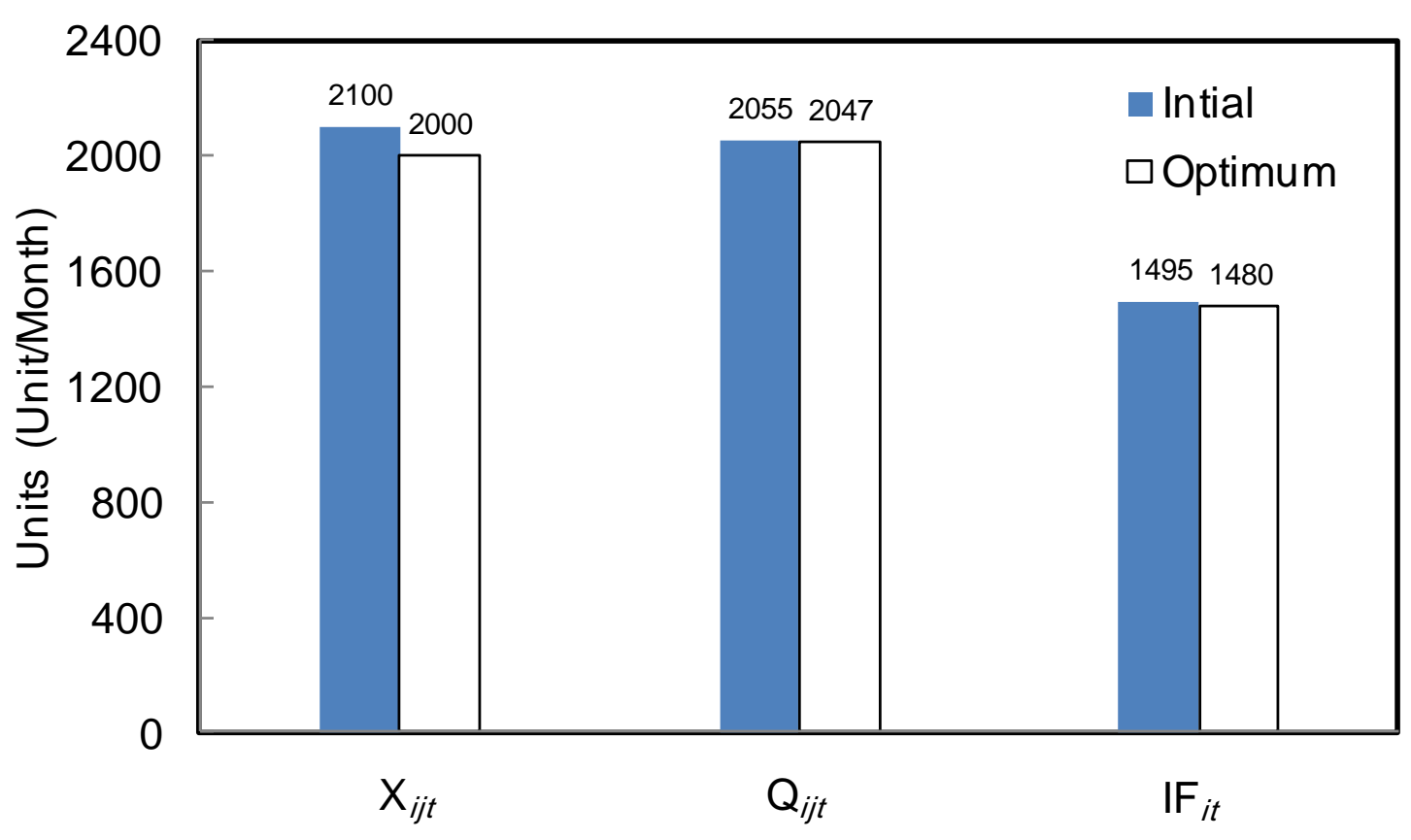

Effective Variable Parameters for EWH2

Fig. 4. Comparison between initial and optimal values of variables for EWH2. 


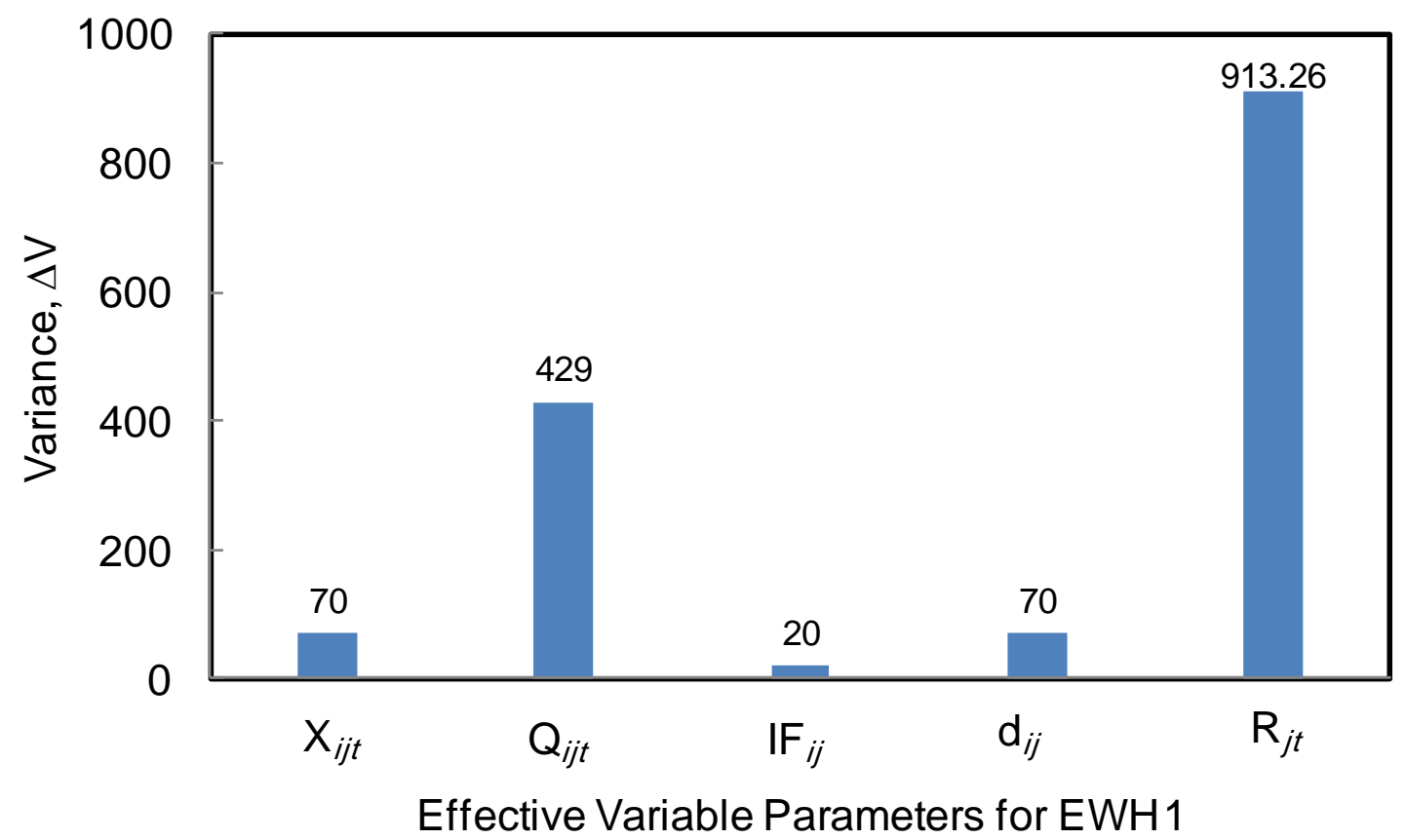

Fig. 5. Variation of effective variable parameters with the variance for EWH1.

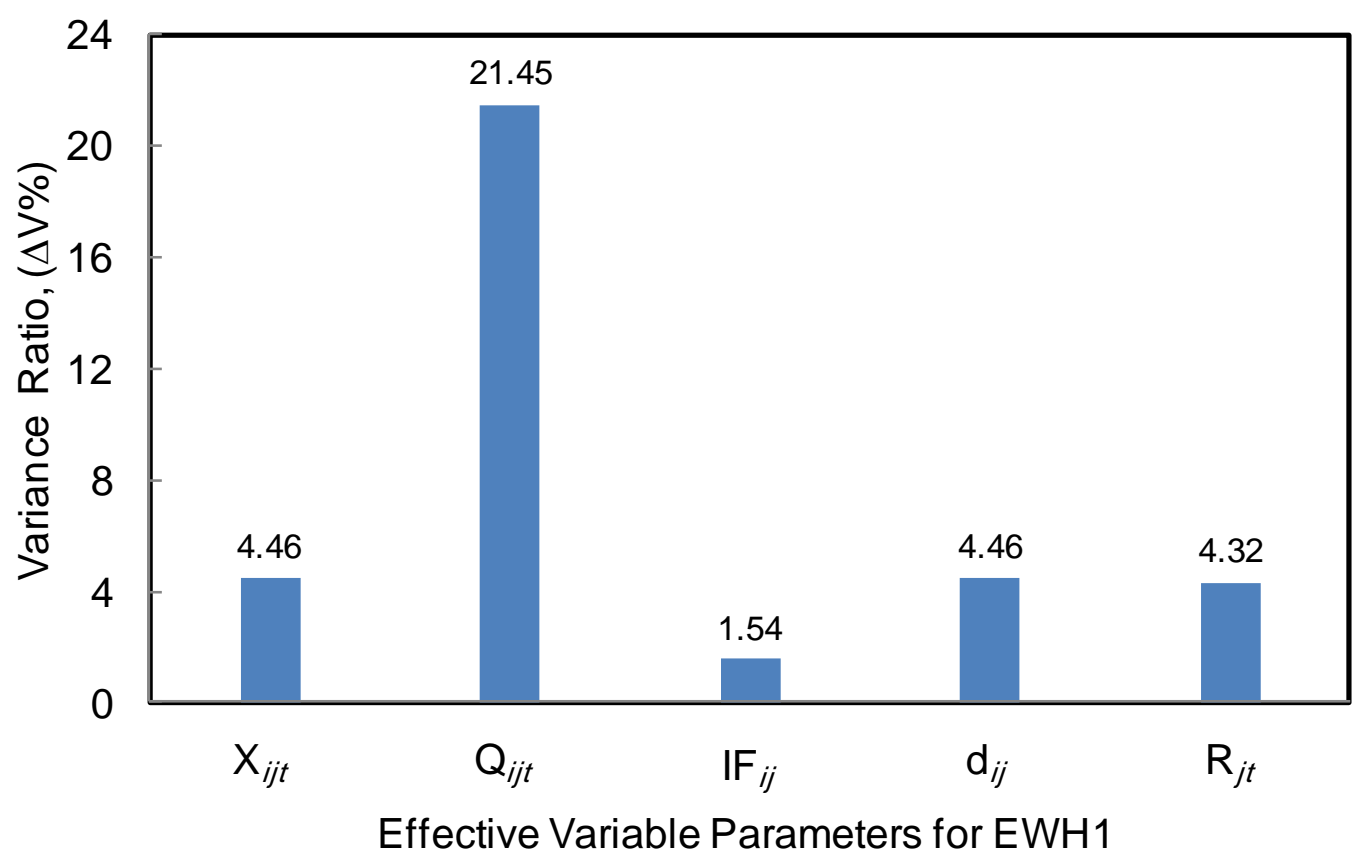

Fig. 6. Variation of effective variable parameters with the variance ratio for EWH1. 


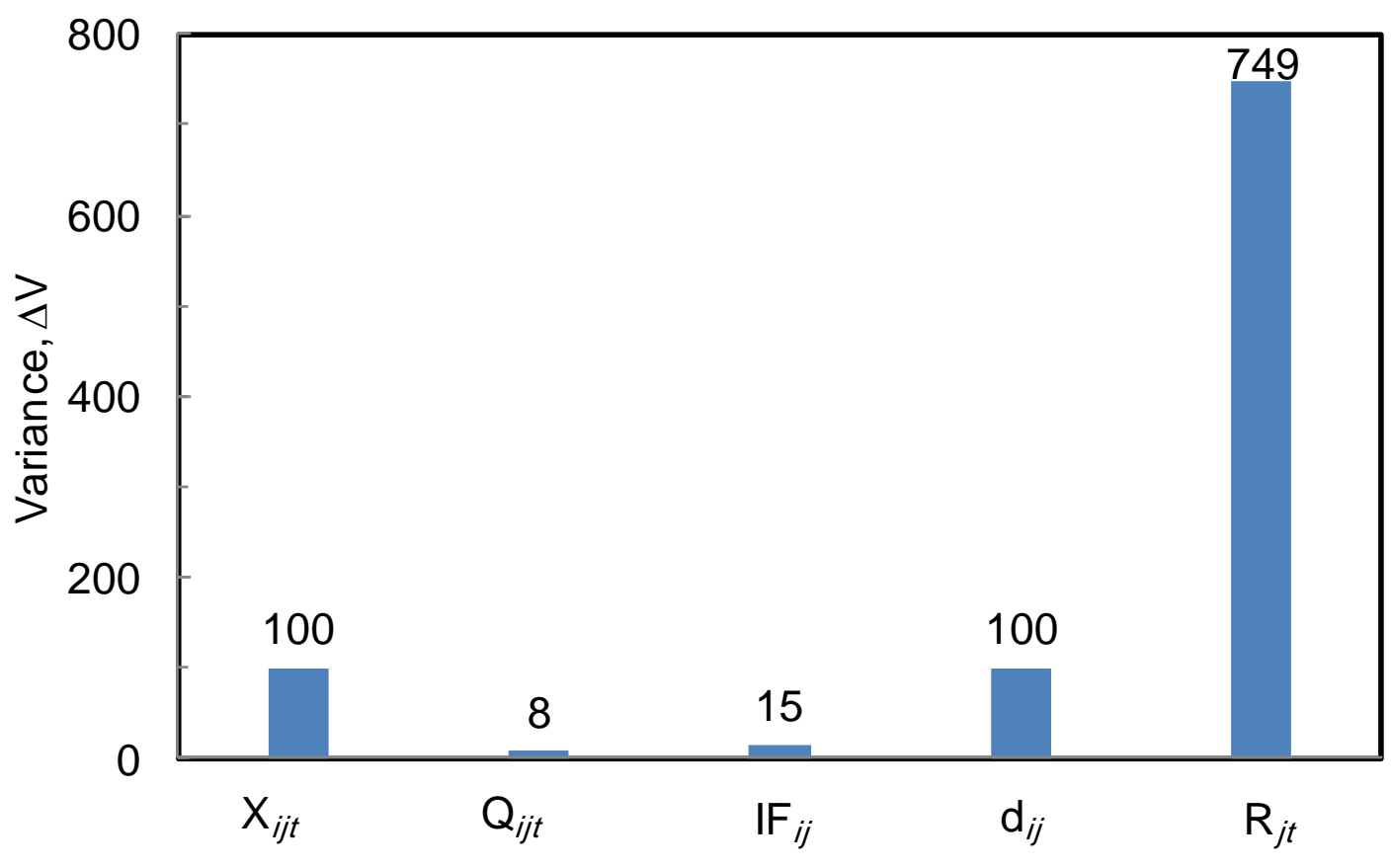

Effective Variable Parameters for EWH2

Fig. 7. Variation of effective variable parameters with the variance for $\mathrm{EWH} 2$.

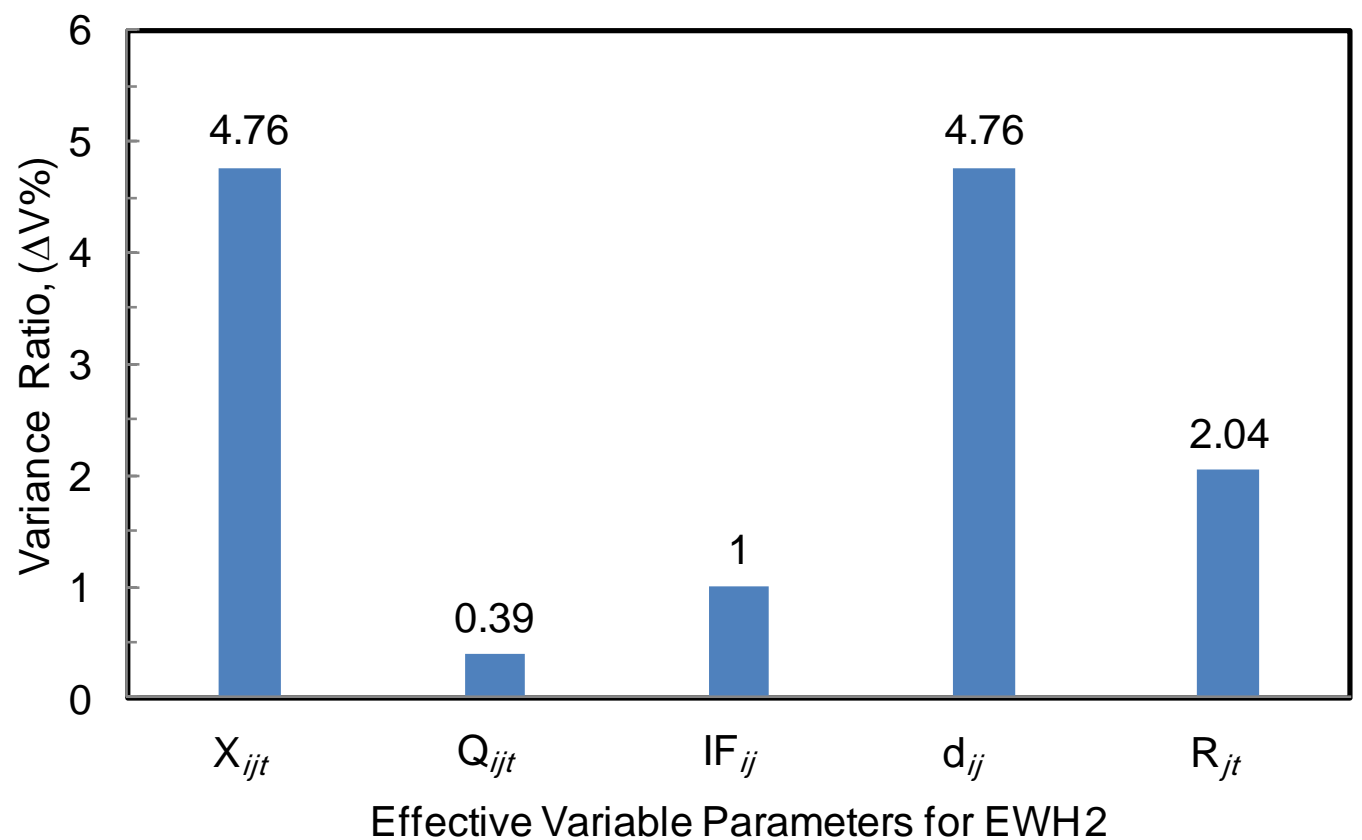

Fig. 8. Variation of effective variable parameters with the variance ratio for $\mathrm{EWH}$. 


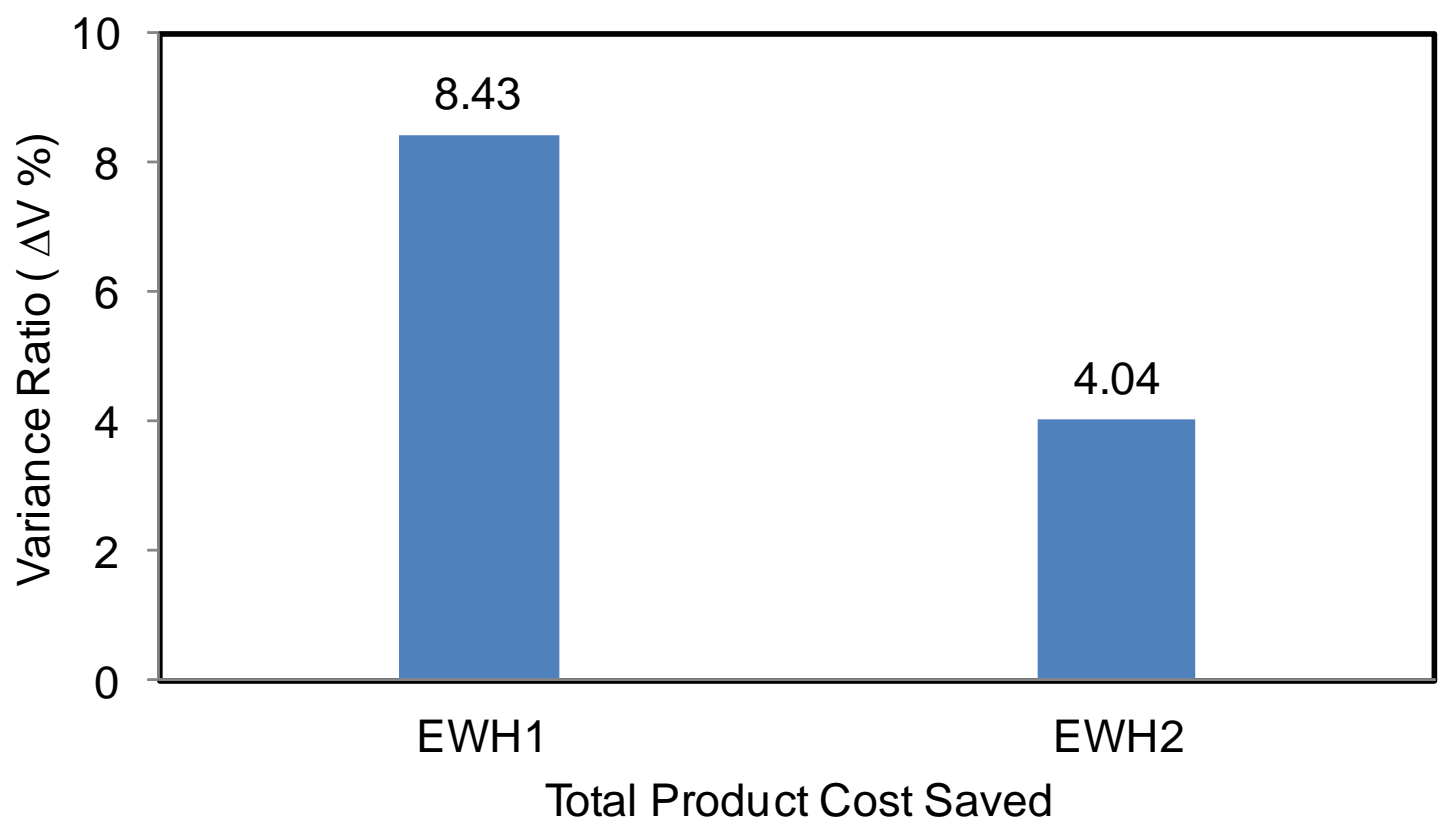

Fig. 9. The total product costs saved against the variance ratio.

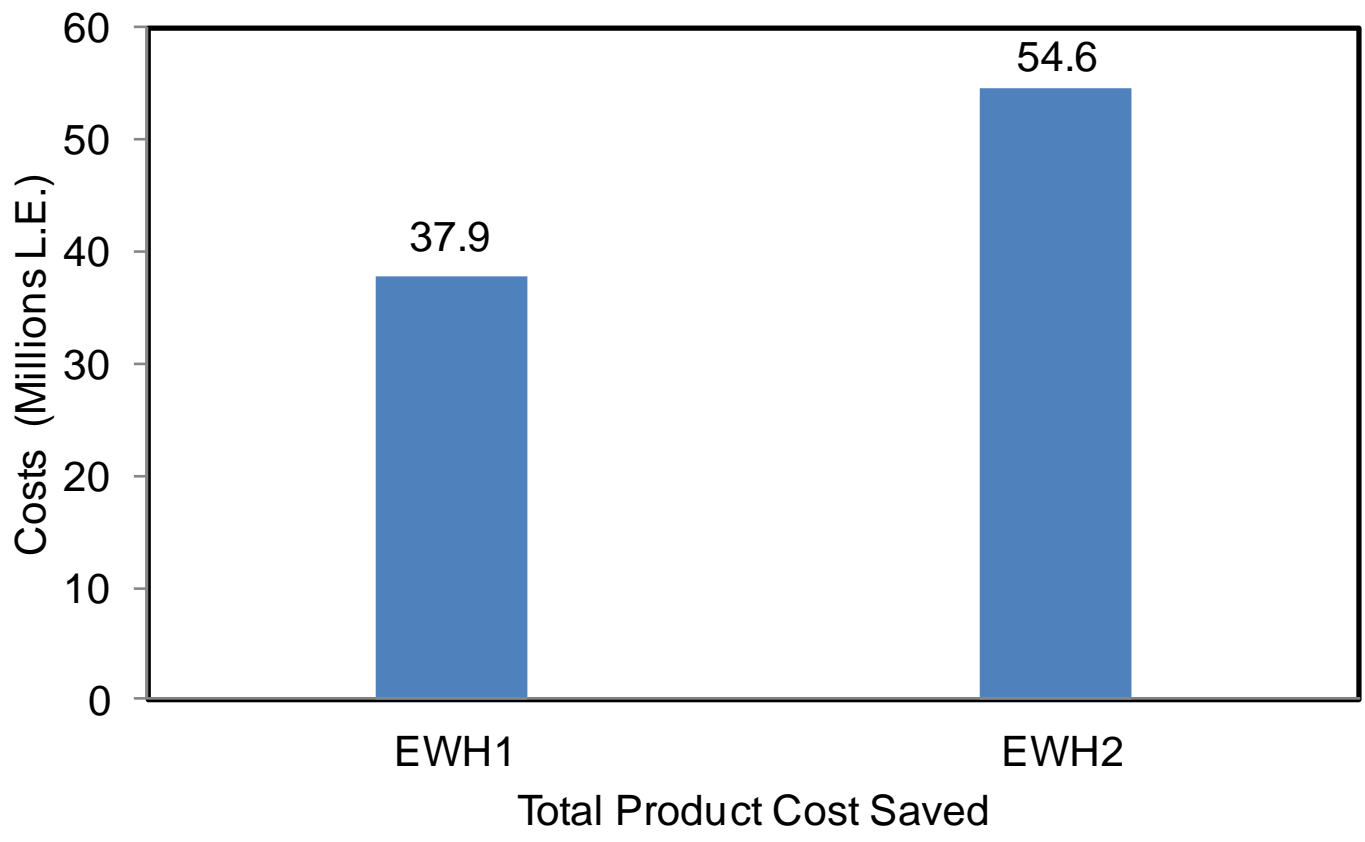

Fig. 10. The total product costs saved for the two cases EWH1 and EWH2. 
Table 1. Different parameters used through data collection (Fixed parameters).

\begin{tabular}{|l|c|}
\hline \multicolumn{1}{|c|}{ Parameters } & Set of Values \\
\hline Total number of items, $\mathrm{k}$ & 65 \\
\hline Total number of resources, $\mathrm{L}$ & 5 \\
\hline No. of periods, $\mathrm{T}$ & 1 \\
\hline No. of sub periods, $\mathrm{w}$ & 4 \\
\hline Cost of production, $C_{i j t}$ & $\mathrm{UN} \sim[500,750]$ \\
\hline Cost of regular time, $r_{i t}$ & $\mathrm{UN} \sim[80,100]$ \\
\hline Inventory holding cost, $h_{i t}$ & $\mathrm{UN} \sim[10,12]$ \\
\hline Setup cost for the families, $B P_{i j}$ & $\mathrm{UN} \sim[50,65]$ \\
\hline Processing time, $P R_{k l}$ & $\mathrm{UN} \sim[0.07,0.075]$ \\
\hline No. of operation per part & 130 \\
\hline Setup time, $b p_{i j}$ & $\mathrm{UN} \sim[0.361,0.331]$ \\
\hline $\begin{array}{l}\text { Total time required to produce one unit } \\
\text { of family } i \text { at cell } j, a_{i j}\end{array}$ & $\mathrm{UN} \sim[3.37,4.5]$ \\
\hline
\end{tabular}

Table 2. Comparison between Initial and Optimal values of different Variables for EWH1 Product.

\begin{tabular}{|c|c|c|c|c|}
\hline Variables & IV & OP & $\Delta \mathbf{V}$ & $\Delta \mathbf{V} \%$ \\
\hline $\begin{array}{l}C_{i j t} \\
\text { ( L.E/Unit) }\end{array}$ & 500 & 510 & -10 & -2 \\
\hline $\begin{array}{ll}X_{i j t} & \text { (Unit/ Month) }\end{array}$ & 1570 & 1500 & 70 & 4.46 \\
\hline$B P_{i j}$ ( L.E/ Month) & 233 & 320 & -87 & -37.34 \\
\hline$Q_{i j t} \quad$ (Unit/ Month) & 2000 & 1571 & 429 & 21.45 \\
\hline$R_{j t} \quad(\mathrm{~h} /$ Month $)$ & 21164.73 & 20251.47 & 913.26 & 4.32 \\
\hline $\begin{array}{ll}h_{i t} & (\mathrm{~L} . \mathrm{E}) \\
\end{array}$ & 40 & 45 & -5 & -12.5 \\
\hline$I F_{i t}$ (Unit/ Month) & 1295 & 1275 & 20 & 1.54 \\
\hline $\begin{array}{ll}D_{i t} & \text { (Unit/Month) }\end{array}$ & 1569 & 1499 & 70 & 4.46 \\
\hline 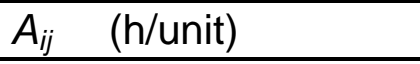 & 13.48 & 13.5 & -0.02 & -0.15 \\
\hline$B O_{i j}(\mathrm{~h} /$ unit) & 1.44 & 1.54 & -0.1 & -6.94 \\
\hline$D_{k t w}$ (Unit/ Month) & 68595 & 68589 & 6 & 0.01 \\
\hline$Z_{\text {kitw }}$ (Unit/ Month) & 68596 & 68590 & 6 & 0.01 \\
\hline$I_{k t w}$ (Unit/ Month) & 323.75 & 318.75 & 5 & 1.54 \\
\hline$R R_{/ t}$ (h/ Month) & 21165.02 & 22634.78 & -1469.76 & -6.94 \\
\hline$P R_{k l}(\mathrm{~h} /$ Month) & 0.3085 & 0.33 & -0.0215 & -6.97 \\
\hline $\begin{array}{l}\text { Total Product Cost, Z } \\
\text { (L.E/Month) }\end{array}$ & $4.49 \mathrm{E}+08$ & $4.11 \mathrm{E}+08$ & 37850400 & 8.43 \\
\hline \multicolumn{5}{|l|}{ V: Initial value } \\
\hline \multicolumn{5}{|l|}{ DP: Optimum value } \\
\hline \multicolumn{5}{|c|}{$\Delta \mathrm{V}=$ Initial value - Optimum value } \\
\hline \multicolumn{5}{|c|}{$\Delta \mathrm{V} \%=(\Delta \mathrm{V} /$ Initial value $){ }^{*} 100$} \\
\hline
\end{tabular}


Table 3. Comparison between Initial and Optimal Variables Values for the EWH2 Product

\begin{tabular}{|c|c|c|c|c|}
\hline Variables & IV & OP & $\Delta \mathbf{V}$ & $\Delta \mathbf{V} \%$ \\
\hline$C_{i j t} \quad$ ( L.E/Unit) & 750 & 780 & -30 & -4.00 \\
\hline$X_{i j t}$ (Unit/ Month) & 2100 & 2000 & 100 & 4.76 \\
\hline$B P_{i j}($ L.E/ Month) & 210 & 260 & -50 & -23.81 \\
\hline$Q_{i j t}$ (Unit/ Month) & 2055 & 2047 & 8 & 0.39 \\
\hline$R_{j t}(\mathrm{~h} /$ Month $)$ & 36751.25 & 36001.29 & 749.96 & 2.04 \\
\hline$H_{i t} \quad($ L.E $)$ & 47 & 48 & -1 & -2.13 \\
\hline$I F_{i t}$ (Unit/ Month) & 1495 & 1480 & 15 & 1.00 \\
\hline$D_{i t}$ (Unit/ Month) & 2099 & 1999 & 100 & 4.76 \\
\hline$A_{i j}$ (h/unit) & 17 & 18 & -1 & -5.88 \\
\hline$B O_{i j}$ (h/unit) & 1.22 & 1.32 & -0.1 & -8.20 \\
\hline$D_{k t w}$ (Unit/ Month) & 74425 & 74416 & 9 & 0.01 \\
\hline$Z_{\text {kitw }}$ (Unit/ Month) & 104778.7 & 102710.3 & 2068.4 & 1.97 \\
\hline$I_{k t w}$ (Unit/ Month) & 373.75 & 370 & 3.75 & 1.00 \\
\hline$R R_{I t}$ (h/ Month) & 36751.5 & 36001.54 & 749.96 & 2.04 \\
\hline$P R_{k l}$ (h/ Month) & 0.35 & 0.35 & 0 & 0.00 \\
\hline $\begin{array}{l}\text { Total Product Cost, Z } \\
\text { (L.E/Month) }\end{array}$ & $1.35 \mathrm{E}+09$ & 1.30E+09 & 54576000 & 4.04 \\
\hline \multicolumn{5}{|l|}{ IV: Initial value } \\
\hline \multicolumn{5}{|l|}{ OP: Optimum value } \\
\hline \multicolumn{5}{|c|}{$\Delta \mathrm{V}=$ Initial value - Optimum value } \\
\hline \multicolumn{5}{|c|}{$\Delta \mathrm{V} \%=(\Delta \mathrm{V} /$ Initial value $) * 100$} \\
\hline
\end{tabular}

